\title{
Adolescentes como sujeitos de pesquisa: \\ a utilização do genograma como apoio para a história de vida*
}

Mariana Gomes Cardim ${ }^{1}$

Martha Cristina Nunes Moreira ${ }^{2}$

CARDIM, M.G.; MOREIRA, M.C.N. Adolescents as research subjects: use of genograms as support for life history. Interface - Comunic., Saude, Educ., v.17, n.44, p.133-43, jan./mar. 2013.

Genograms consist of graphical representation of consanguineous families, kinship and/or affective relationships, and provide information on various dimensions of family dynamics. The empirical basis of this paper was reflection about the background of preparation, use and preliminary analysis of the process of using genograms as a research development technique. Thus, the design of this study favored the perspective of thematic histories of the lives of 14 adolescents who were living with HIV/AIDS due to vertical transmission. Genograms were considered to be an important resource for initially approaching the adolescents, through facilitating a closer and more relaxed relationship between the researcher and the subject. They were also considered to be suitable for data gathering, as investigative instruments. Moreover, they were seen to be an important tool for enabling the researcher to understand the life histories reported by the adolescents.

Keywords: Genogram. Adolescents. Life history
O genograma consiste na representação gráfica da família consanguínea, de parentesco e/ou afetividade, trazendo informações sobre várias dimensões da dinâmica familiar. O presente artigo tem como base empírica a reflexão sobre os bastidores da elaboração, utilização e análise preliminar do processo de utilização do genograma como técnica no desenvolvimento de uma pesquisa cujo desenho privilegia a perspectiva da história de vida temática, com 14 adolescentes que vivem com HIV/Aids por transmissão vertical. O genograma foi considerado um importante recurso para a abordagem inicial do adolescente, facilitando a aproximação e descontraindo a relação entre o pesquisador e o sujeito da pesquisa; mostrou-se adequado para a apreensão de dados, como um instrumento de pesquisa; e revelou-se, ainda, uma importante ferramenta para o pesquisador entender a história de vida contada pelos adolescentes.

Palavras-chave: Genograma. Adolescentes. História de vida.
* Elaborado com base em Cardim (2012);

pesquisa aprovada pelo Comitê de Ética em Pesquisa do Instituto Fernandes Figueira (IFF/Fiocruz).

1 Serviço de Doenças Infecciosas em Pediatria, IFF, Fiocruz. Av.

Embaixador Abelardo Bueno, 2510, bloco 1, apto. 1508, Barra da Tijuca. Rio de Janeiro, RJ, Brasil. 22.775-040. maricardim@gmail.com

${ }^{2}$ Programa Saúde \& Brincar, Departamento de Pediatria, IFF, Fiocruz. 


\section{Introdução}

Investigar o protagonismo de sujeitos cuja autonomia encontra-se referida aos adultos, no caso crianças e adolescentes, significa estudar suas contribuições como agentes transformadores da cultura, e não somente resultados de processos de socialização. Essa afirmação é ponto de partida de uma série de estudos que investem na revisão crítica sobre a representação cultural da posição ocupada por esse segmento como sujeitos passivos frente às normas e instituições (Delgado, Muller, 2005; Mollo-Bouvier, 2005; Plaisance, 2004; Castro, 2001; Montandon, 2001; Sirota, 2001; Groppo, 2000; Mayall, 1998; Pais, 1990). Nesse argumento vale reafirmar a diferença entre realizar estudos sobre as crianças e adolescentes ou com as crianças e adolescentes (Moreira, Macedo, 2009), assumindo, inclusive, as interfaces éticas (Guariglia, Bento, Hardy, 2006) no reconhecimento de uma autonomia que aqui denominamos gerenciada, porque é submetida aos cuidadores responsáveis.

Estima-se que quatrocentas e trinta mil novas infecções pelo HIV ocorreram entre crianças menores de 15 anos de idade em 2008. Acredita-se que a maioria desses novos casos seja resultado de transmissão vertical. Porém, este número teve redução de, aproximadamente, $18 \%$ em comparação com o ano de 2001 (WHO, 2009). No Brasil, estimou-se, em 2004, que 12.456 recém-nascidos sejam expostos ao HIV anualmente, sendo a taxa estimada de transmissão vertical do HIV de 6,8\% (Brasil, 2010). Apesar dos grandes progressos alcançados na prevenção de novas infecções pelo HIV e na redução do número anual de óbitos relacionados à Aids, o número de pessoas que vivem com HIV continua a aumentar. Doenças relacionadas à Aids continuam sendo uma das principais causas de morte no mundo e são projetadas para continuar como uma causa significativa global de mortalidade prematura nas próximas décadas. Diante disso, a Organização Mundial de Saúde continua a considerar a Aids como prioridade de saúde global (WHO, 2009).

Os adolescentes que vivem com o HIV/Aids constituem uma população heterogênea no que se refere à forma e a idade em que ocorreu a transmissão (vertical ou horizontal), com consequências diferentes para suas condições clínicas, imunológicas, psicossociais, culturais e histórico de tratamento (Brasil, 2009). Dado isso, faz-se necessário assumir, nas transformações no perfil de morbimortalidade por HIV/Aids, a realidade de uma doença que se revela crônica. De crianças que, tendo nascido com HIV, podem ou não desenvolver a doença, e, por isso mesmo, vivem e convivem com rotinas de medicação, tratamento e visitas frequentes às instituições de saúde, chegando à adolescência e tendo que gerenciar revelações de diagnóstico, rotinas e estigmas / marcas simbólicas da doença (Moreira, Cunha, 2003).

Nesse sentido, considerando que a geração de crianças que nasceram e vivem com o HIV/Aids compõe hoje um contingente importante de adolescentes que, um dia, chegarão à idade adulta, vale acessar suas experiências, desvelando seus aprendizados, dificuldades, descobertas e histórias que parecem atravessadas pela condição de gerenciamento. Esse gerenciamento qualifica sua atitude frente a sua história, marcada por: condições de segredo, revelação, mediação de sua autonomia na interface com os estigmas da doença.

O presente artigo tem como base empírica a reflexão sobre os bastidores da elaboração, utilização e análise preliminar do genograma em uma pesquisa, ainda em curso, com adolescentes que vivem com HIV/Aids por transmissão vertical, cujo desenho privilegia a perspectiva da história de vida temática, com base teórico-analítica assentada no interacionismo simbólico (Simmel, 2006; Goffman, 1988).

A pesquisa foi aprovada pelo CEP/IFF/Fiocruz e obedeceu aos princípios de voluntariedade, confidencialidade e anonimato. E ainda, contou com devolutivas parciais para os sujeitos sobre possíveis apoios que se fizessem necessários para seu tratamento de saúde junto à instituição, sendo compartilhados com os sujeitos logo após o fim das entrevistas, e informados às equipes para garantir o direito à saúde. 


\section{Os bastidores da pesquisa com adolescentes que vivem com HIV/Aids por transmissão vertical: teoria e instrumentos}

Tendo como guia a necessidade de acessar o conhecimento e a história de adolescentes que vivem com HIV/Aids, assumimos como condição ter esse grupo como sujeitos de pesquisa. Ao mesmo tempo, reconhecendo que suas histórias se construíram na interface com as histórias de seus responsáveis, considerados participantes ativos no cuidado a esta clientela, os incluímos como sujeitos também.

A coleta de dados se deu por meio da técnica de entrevista de História de Vida, assumindo como foco o tratamento de saúde e seu gerenciamento pelo adolescente e seu cuidador, valorizando personagens e lugares que compõem o cenário de vida de uma pessoa. $\mathrm{E}$, nesse desenho, torna-se possível acessar a compreensão e interpretação das variáveis que influenciam e/ou determinam a construção de determinado itinerário terapêutico pelos adolescentes que vivem com HIV/Aids por transmissão vertical. Reunindo presente, passado e possíveis projeções de futuro, o sujeito reconstrói sua experiência pessoal associada ao contexto dos significados que ele desvela. Segundo Minayo (2010), o recurso à história de vida revela-se um poderoso instrumento para a descoberta, a exploração e a avaliação de trajetórias temporais. Quanto ao significado do termo história de vida, a partir do vocábulo francês "historie", a língua inglesa dispõe de duas palavras para a tradução - story e history. Segundo Bertaux apud Spindola e Santos (2003), em 1970, o sociólogo americano Denzin propôs a distinção das terminologias life story e life history. Para o pesquisador, life history (ou estudo clínico) compreende o estudo aprofundado da vida de indivíduos ou grupos. Inclui, além da própria narrativa de vida, todos os documentos que possam ser consultados e/ou depoimentos de outras pessoas para comprovação da veracidade do que foi narrado pelo sujeito do estudo. Já a life story (ou narrativas de vida) considera o relato de vida da pessoa, da maneira em que ela vivenciou. Nesse caso, a autenticidade dos fatos não é confirmada pelo pesquisador, pois o essencial é o ponto de vista da pessoa que está narrando.

Assim, diante dos adolescentes e de seus cuidadores, valorizamos sua life story compreendendo que, na trajetória de gerenciamento da doença, identificamos, inicialmente, como protagonista da trajetória, o responsável e, posteriormente, o adolescente.

Importante destacar que, na área da pesquisa em saúde, a história de vida tem sido trabalhada de maneira mais restrita a um evento ou época da vida, sendo, portanto, denominada de história de vida focal (Bellato, Araujo, Castro; 2008). Diante disso, adotamos este termo por ser pertinente ao nosso propósito, qual seja o de enfocar, através das narrativas, a experiência de adoecimento, o manejo e o impacto da enfermidade e a busca por cuidados às necessidades de saúde.

No entanto, a abordagem da pesquisa teve como prerrogativa entrevistar adolescentes separados de suas mães, o que transcorreu sem problemas, com concordância de ambas as partes. Vale ressaltar que, para uma das adolescentes entrevistadas, esse momento separado da mãe foi uma novidade na relação que essa última tinha estabelecido durante a história de tratamento da filha na instituição cenário de pesquisa. Esse retorno foi dado pela equipe logo após o encerramento do processo de entrevista com as duas.

Ao aceitarem participar, foram orientados sobre o tema, o objeto, os objetivos da pesquisa, e foi apresentado um Termo de Consentimento Livre e Esclarecido (TCLE) para os responsáveis dos adolescentes que compuseram a população do estudo; e, para os adolescentes, elaboramos um Termo de Assentimento Livre e Esclarecido, com vistas a valorizar o adolescente como sujeito de pesquisa. Tal esforço busca demarcar objetivamente as afirmações sobre a particularidade e os desafios de se considerar adolescentes como sujeitos de pesquisa, atores participantes de sua história, e não meros assistentes de um processo (Mello, Moreira, 2010; Guariglia, Bento, Hardy, 2006).

Outra base importante, no processo de elaborar o projeto de pesquisa e no seu processo de entrada em campo, foi refletir sobre instrumentos adequados e verdadeiramente adaptados para o respeito à condição de adolescer e adoecer com HIV/Aids. Ou seja, inspirados pela discussão de Simmel (2006) sobre a dimensão lúdica da vida, procuramos assumir que a abordagem dos adolescentes valorizava a experiência deles, e essa era significativa e fundamental, digna de ser acessada e analisada. Assim, 
precisaríamos conquistá-los para o encontro de pesquisa. Daí assumirmos a utilização de uma conversa mediada e antecedida pelo desenho de sua rede familiar de referência, via o recurso ao genograma.

O genograma consiste na representação gráfica - através de símbolos e códigos padronizados - da família consanguínea e/ou de parentesco e/ou afetividade, de modo a compreender sua composição transgeracional, a qualidade de seus vínculos e seus núcleos cuidadores, evidenciando as redes para o cuidado em saúde tecidas por pessoas e famílias, de modo a dar-Ihes sustentação e apoio na experiência de adoecimento e cuidado (Costa et al., 2009).

Esta simbologia foi padronizada por um comitê organizado no início da década de 1980, o Grupo Norte-Americano de Pesquisa em Atenção Primária (North American Primary Care Research Group), que definiu os símbolos práticos a serem utilizados no genograma. Assim, os elementos da família são representados por um quadrado, para as pessoas do sexo masculino, ou por um círculo, para as pessoas do sexo feminino. Os casais são ligados por linha horizontal e, sobre esta, as datas do casamento e, se for o caso, da separação e divórcio, conforme as informações colhidas. Todas as datas de eventos relevantes são registradas para que sejam estabelecidas correlações contextuais na análise posterior. As mortes, doenças e transtornos dos indivíduos são assinalados no próprio genograma, facilitando sua imediata identificação (Muniz, Eisenstein, 2009).

Assim, apesar de similar à árvore genealógica, esta ferramenta vai além da representação visual da origem dos indivíduos, uma vez que traz informações sobre dimensões da dinâmica familiar, como: processos de comunicação, relações estabelecidas, equilíbrio/desequilíbrio familiar, eventos importantes na história do indivíduo (como separações, mortes e nascimentos) e laços funcionais (Nascimento, Rocha, Hayes, 2005).

O genograma, juntamente com o ecomapa, tem sido valorizado como importante instrumento na compreensão dos processos familiares e no reconhecimento do nível de relação estabelecida com os recursos disponíveis na comunidade. Nessa direção, tem sido muito utilizado na terapia familiar e em estudos no âmbito: da saúde da família, de cuidados com pessoas com doenças crônicas e mentais, idosos, de redes de apoio e de compreensão do contexto familiar no processo saúde e doença (Charepe et al., 2011; Pereira et al., 2009; Bellato, Araújo, Castro, 2008; Pavarine et al., 2008; Nascimento, Rocha, Hayes, 2005; Simpionato, Correia, Rocha, 2005).

Para os profissionais de saúde, essa ferramenta tem se tornado uma grande aliada do cuidado, uma vez que o conhecimento do funcionamento da família, de suas características, do contexto social, cultural e econômico no qual está inserida, é de fundamental importância para a realização do planejamento das intervenções de saúde.

Este recurso foi utilizado, ainda, como um elemento facilitador para a construção da história com os adolescentes, uma vez que o processo de construção conjunta do genograma traz uma tônica mais informal e descontraída à coleta de dados, facilitando as relações entre o profissional e o adolescente (Nascimento, Rocha, Hayes, 2005).

Sua diferença com relação a outras técnicas de coleta de dados de pesquisa, tais como entrevistas, observações, questionários, se situa no âmbito da capacidade de promover uma interação que retoma o lugar do sujeito na sua família, ou, até mesmo, no âmbito das relações que ele atribui como familiares, além de participar ativamente no processo. Ou seja, o genograma, adaptado como técnica de pesquisa, pode contribuir para o estudo do sujeito em relação, e, ainda, para o encontro lúdico - linguagem preferencial de comunicação da criança e do jovem (Santa Rosa, 1993) - já que, no caso da presente pesquisa, buscaram-se personagens na forma de desenho, que contribuíam para um ambiente de prazer e envolvimento.

\section{A técnica do genograma: o caminho percorrido}

O genograma foi utilizado como um dos instrumentos de coleta de dados durante o desenvolvimento de uma pesquisa qualitativa de tese de doutorado, que tinha como objetivo a compreensão da experiência de adoecimento e cuidado vivenciada por adolescentes com HIV/Aids por 
transmissão vertical e sua família, trazendo à tona os seus itinerários terapêuticos, os fatores que dificultam e as estratégias que auxiliam o seguimento da terapia.

A instituição selecionada para a realização do estudo foi o Instituto Nacional de Saúde da Mulher, da Criança e do Adolescente Fernandes Figueira (IFF/Fiocruz), especificamente, no ambulatório de Doenças Infecciosas Pediátricas (DIPe), onde as famílias foram abordadas para a participação no estudo. Este ambulatório tem como foco principal a atenção às crianças e adolescentes que vivem com HIV/ Aids e bebês expostos ao vírus HIV durante a gestação.

Os sujeitos do estudo foram adolescentes que vivem com HIV/Aids após transmissão vertical e são acompanhados no ambulatório de DIPe do IFF e seus responsáveis. O critério etário para a participação do adolescente no estudo foi de 12 a 18 anos, período de vida considerado como adolescência pelo ECA. Os critérios de exclusão para participação foram: Adolescentes que ainda não conheciam o seu diagnóstico; Adolescentes que se encontravam em condições de debilidade física e emocional; Adolescentes com agravos neurológicos, que os impediam de expressar suas opiniões; Adolescentes que nunca fizeram uso de medicação antirretroviral; e aqueles em que o próprio e/ou seu responsável não concordassem com a assinatura do Termo de Consentimento Livre e Esclarecido.

A amostra foi do tipo intencional por conveniência. Convidavam-se, para participar, os adolescentes e seus responsáveis que preenchiam os critérios de inclusão/exclusão e que estavam disponíveis na sala de espera do Ambulatório de DIPe, aguardando consulta de rotina, levando-os para uma sala reservada do próprio ambulatório.

Os adolescentes e seus responsáveis foram convidados a participar da pesquisa pessoalmente. Foram deixados à vontade em relação a participarem ou não. Foram orientados de que não haveria qualquer repercussão no atendimento, caso não concordassem em participar, e teriam acesso às entrevistas, se assim o desejassem. Também foram esclarecidos sobre a garantia do resguardo de suas identidades, assim como, do direito de retirarem seus consentimentos em qualquer fase da pesquisa, sem penalização alguma, conforme descreve a Resolução 196/96.

Para viabilizar o aprofundamento do conhecimento da temática em estudo, a partir da ótica de quem vivencia o problema, da subjetividade do indivíduo em condição crônica, ou seja, os adolescentes que vivem com HIV/Aids e seus responsáveis, optamos por utilizar o método de História de Vida, por considerá-lo o mais apropriado para possibilitar a compreensão e interpretação das variáveis que influenciam e/ou determinam a construção de determinado itinerário terapêutico pelos adolescentes que vivem com HIV/Aids por transmissão vertical.

É importante destacar que, com o adolescente, a entrevista de história de vida foi antecedida de um instrumento lúdico, que visa construir um genograma através de um desenho da rede de pessoas e /ou instituições de referência para ele (Charepe et al., 2011).

Juntamente com a entrevista, foi realizada uma observação de campo, e, através de um caderno/ diário de campo, foram anotadas: todas as observações, as reações não verbais (pausas, gestos, expressões, comportamentos...), os sentimentos aflorados e as reflexões. Esse material é de grande importância tendo em vista que "a entrevista, quando analisada, precisa incorporar o contexto de sua produção e, sempre que possível, ser acompanhada e complementada por informações provenientes de observação" (Minayo, 2010, p. 263). Além disso, esse material foi extremamente importante para o relato de experiência apresentado neste estudo.

A coleta de dados ocorreu entre os meses de fevereiro e março de 2012, e participaram deste estudo 14 adolescentes, com seus respectivos responsáveis, sendo sete adolescentes do sexo masculino e sete do sexo feminino.

Os encontros foram gravados, desde o momento da construção do genograma com o adolescente até a entrevista de história de vida, por intermédio de gravador digital (MP3 player), em local tranquilo e reservado, onde os depoentes puderam se sentir à vontade para falar. Não houve tempo preestabelecido para a gravação dos depoimentos. Os adolescentes foram identificados de acordo com a ordem das entrevistas, através de números arábicos, garantindo-lhes seu anonimato. 


\section{Resultados e discussão: a experiência em reflexão}

A construção do genograma era proposta ao adolescente e ofertados os materiais, compostos por: cartolina, cola, canetas e várias gravuras recortadas com personagens femininos e masculinos. $O$ processo de construção era feito em conjunto com o pesquisador, que o auxiliava na confecção e colagem das gravuras (Figura 1).

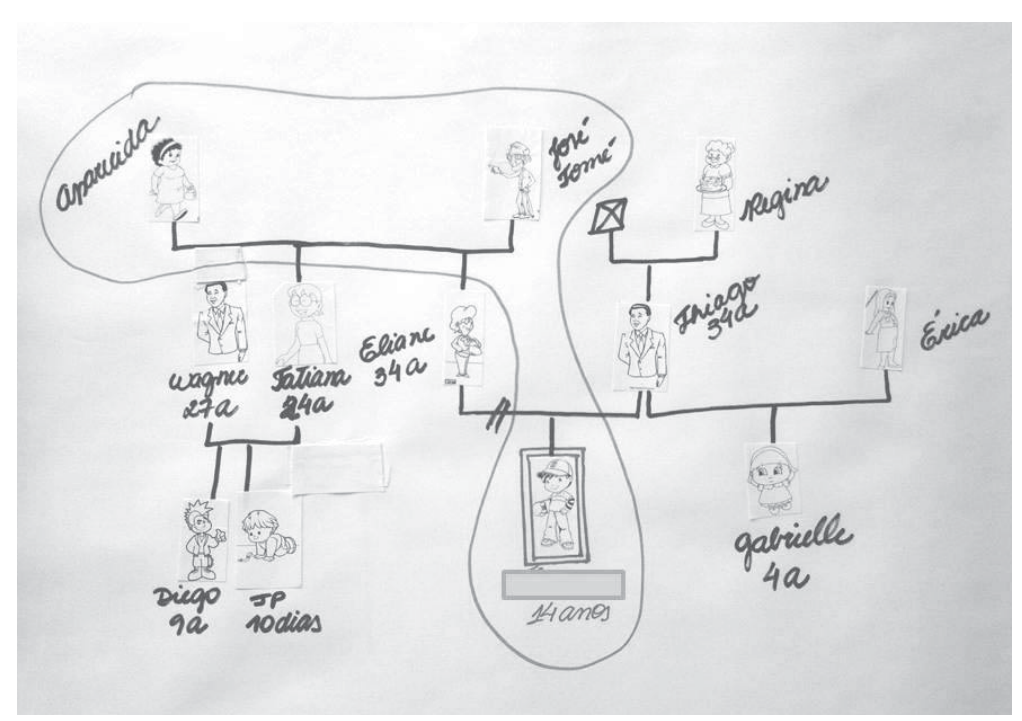

Figura 1. Genograma adolescente 6

Esse recurso, inclusive na faixa etária dos adolescentes, não era estranho ao seu repertório, sendo comum a fala de que, na escola e nas aulas de biologia, já tinha sido vista a árvore genealógica, que possui uma estrutura parecida com a do genograma.

A dinâmica foi vista por todos os entrevistados como uma atividade divertida, estimulante, interativa e ilustrativa. O processo era sempre mediado por muitos risos e descontração, sobretudo no momento da escolha das gravuras que representassem o seu familiar.

\footnotetext{
"Ah, preciso achar a foto de um gordinho pra representar o meu primo. Achei! Hiii, é o
} Nhonho! Se ele visse isso ia querer me matar. [risos]" (adolescente 04)

"Uma gravura pra minha irmã? Ai, que legal" " (adolescente 12)

O genograma, na coleta de dados, transformou-se em uma atividade lúdica. Assim, além de ser fonte de prazer e descoberta para os participantes, constituiu-se, ainda, em elemento facilitador da relação entre o adolescente e o pesquisador, criando um clima informal e descontraído para a coleta de dados.

O elemento lúdico é um facilitador das relações quando os sujeitos em foco são as crianças e os adolescentes, além de possibilitar a eles uma reconstrução simbólica da realidade de uma forma que Ihes agrade (Moreira, Cunha, 2003). O brincar, através de sua ação historiciante, permite que a criança e o adolescente deem sentidos as suas experiências e reorganizem a vivência de adoecimento (Santa Rosa, 1993). 
A realização dessa atividade revelou a percepção de cada adolescente sobre a sua família e os membros que a constituem, acenando para o fato de que não existem modelos nem tipos de famílias preestabelecidos. Nascimento, Rocha e Hayes (2005, p.281) trazem esta questão ao cerne de suas discussões dizendo ser necessário "repensar a família em termos de processo de interações entre pessoas e como elas constroem a noção de família num contexto múltiplo de raça, idade, gênero, preferência sexual, situação socioeconômica, etnicidade, localidade e historicidade".

Com relação a este assunto, vale destacar que alguns dos adolescentes com histórico de adoção não revelaram esta informação durante a construção do genograma, o que pode demonstrar, por hipótese, a preocupação do adolescente com as relações estabelecidas, e não com a genealogia. Uma das adolescentes fez questão de incluir o seu cachorro como membro de família tendo em vista ser "seu grande companheiro".

Os adolescentes que participaram do estudo só revelaram os componentes da família com quem tinham relações estreitas, as pessoas que eram importantes no momento presente.

“Eu acho que tem muitas pessoas que participaram da minha vida. Mas, aí eu pus as que eu tenho mais, sei lá, mais afeto. Ou que, talvez, eu deva colocar. Tem pessoas que são importantes, mas não tão quanto. Sabe?" (adolescente 14)

Essa situação era facilmente visualizada quando os mesmos não escolhiam gravuras de personagens para determinados elementos da família. Geralmente, eram pessoas que precisavam ser identificadas por serem pais, por exemplo, de uma pessoa importante para a sua história (Figura 2). Um dos adolescentes, por exemplo, relatou que seu pai possuía nove irmãos, porém, na estrutura de seu genograma, ele identificou somente duas tias. No momento da entrevista de sua mãe, ao observar o "desenho" projetado do seu filho, comentou que aquelas duas tias identificadas eram as suas "tias do coração".

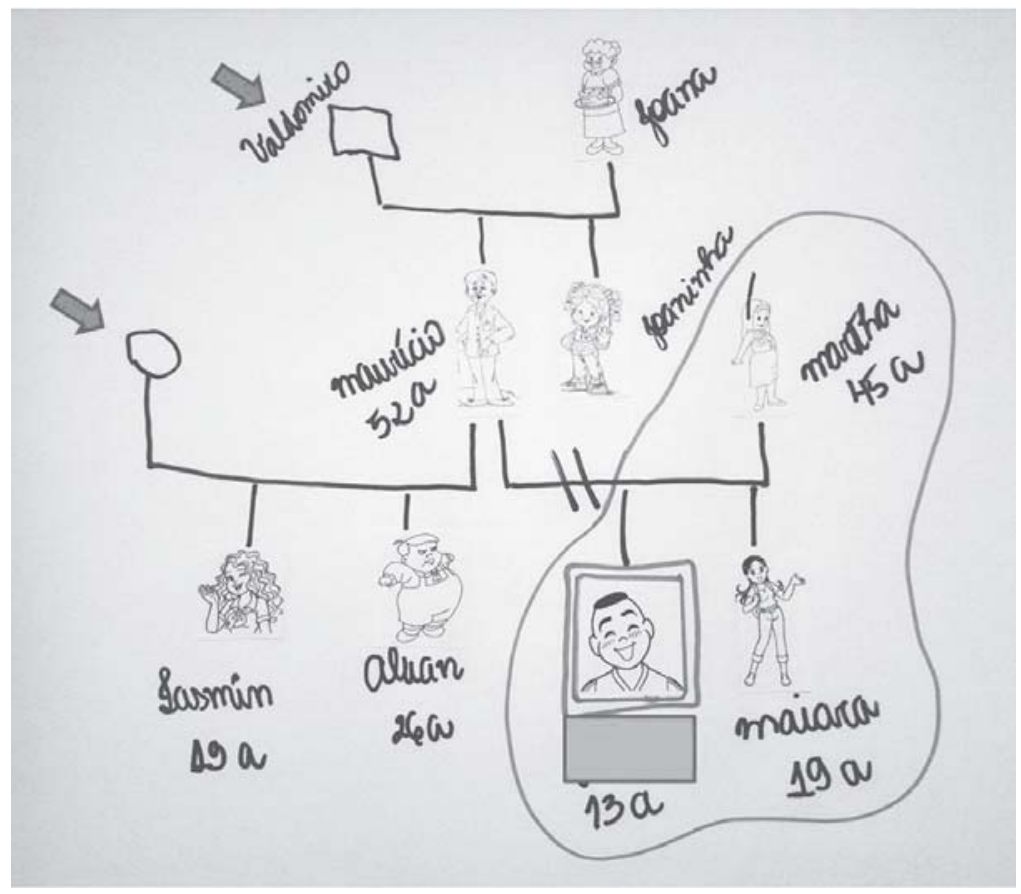

Figura 2. Genograma adolescente 4 
A condição crônica gera uma mudança nos hábitos e rotina de vida que se estende a todo o universo familiar, impondo modificações nas relações familiares a partir de suas práticas e comportamentos cotidianos. A rotina da família se altera através das constantes visitas ao médico e outros especialistas, medicações e hospitalizações, e acaba atingindo todas as pessoas convivendo com a criança (Castro, Piccinini, 2002).

Essa rotina começa a ser tão determinante, tão parte da vida desses indivíduos, que duas adolescentes, por exemplo, identificaram suas médicas no desenho de seus genogramas familiares.

No caso específico dos sujeitos desse estudo - adolescentes que vivem com HIV/Aids - foi possível verificar, posteriormente, durante a narrativa de sua história de vida ou de seus responsáveis, que muitos deles identificavam, no genograma, apenas o seu núcleo familiar (pais, irmãos e pessoas que residem na mesma casa) e os outros membros da família que tinham o conhecimento do seu diagnóstico, como se aquela família fosse formada a partir daquele "segredo do diagnóstico".

A Aids logo se tornou um fenômeno público e coletivo, dado o seu caráter epidêmico, contagioso, incurável e mortal. Em sua história, sua disseminação inicial em grupos específicos associou a infecção pelo HIV às condutas desviantes e, por esse motivo, as pessoas que vivem com a doença eram alvo de julgamento moral e reprovável, gerando estigma e preconceito.

Apesar da revisão de paradigma com relação ao "grupo de risco" e a melhora na qualidade de vida a partir dos antirretrovirais (Brasil, 2009), o início da história ainda é soberano e, em função dos aspectos metafóricos criados e do preconceito, as pessoas com HIV/Aids vivenciam, ainda, emoções singulares, permeadas por um conjunto de aspectos, como medo, morte, culpa e segredo. O sofrimento, nesse contexto repleto de significados, fragiliza o indivíduo, que vivencia situações de ameaça à sua integridade física, emocional e social (Almeida, Labronici, 2007). Todo esse contexto de estigma interfere diretamente na vida pública e privada da pessoa que vive com HIV/Aids.

Nesse sentido, estigma é definido, por Goffman (1988), como um atributo depreciativo, podendo ser entendido como defeito, fraqueza ou desaprovação. Assim, a sociedade desqualifica a pessoa que possui tal atributo, causando uma discrepância entre a identidade social real da pessoa e sua identidade virtual. Deste modo, quando a pessoa que porta o estigma não tem a diferença aparente fisicamente, há a necessidade de manipulação da informação sobre o defeito para que o mesmo não seja descoberto e discriminado.

Diante de todo esse contexto histórico e social da doença Aids, os sujeitos tendem a optar pelo ocultamento da sua sorologia na vida pública/social. Nessa direção, todo o processo de adolescer e, consequentemente, todo o itinerário terapêutico do adolescente que vive com HIV/Aids por transmissão vertical é marcado pelo gerenciamento de um segredo.

O pacto de silêncio parece ser tão forte que a questão da doença fica velada dentro da própria unidade familiar. Essa situação é tão acentuada que marca, inclusive, a construção dos genogramas familiares, reduzindo-os, muitas vezes, às pessoas mais próximas e que compartilham desse segredo. De acordo com Cruz (2007, p.380), "o peso da Aids é tamanho que por vezes as crianças são impedidas até de dizer a palavra Aids".

Além de ter demonstrado ser um importante instrumento de coleta de dados, a construção do genograma permitiu, para alguns adolescentes, a visualização da sua estrutura familiar, trazendo reflexões sobre as suas relações com aquelas pessoas e reflexões sobre suas experiências de vida.

\footnotetext{
“Eu achei bem interessante. Isso é muito bom pras outras pessoas. Isso é ótimo. Isso é uma coisa que pode fazer com que as pessoas parem pra entender, parem pra visualizar a vida delas e entender". (adolescente 01)
}

Uma limitação da construção do genograma apenas com a presença do adolescente como informante refere-se ao fato de não ser possível a construção fidedigna da estrutura familiar, tendo em vista que os mesmos, muitas vezes, não sabem informar idades, número de filhos ou, mesmo, nomes de tios com quem pouco têm contato. Diante disso, essa construção apenas com os adolescentes pode não ser útil em estudos em que essa formação familiar completa seja estritamente necessária. 


\section{Considerações finais}

O processo de construção do genograma foi encarado como um facilitador entre os adolescentes, que enfatizaram a importância da sua realização antes da entrevista. O caráter lúdico permitiu a participação dos adolescentes de maneira intensa, descontraída, prazerosa e interativa. Dessa forma, foi considerado um importante recurso para a abordagem inicial do adolescente, facilitando a aproximação e resgatando, durante sua aplicação, a possibilidade de estabelecimento de uma relação positiva entre o pesquisador e o sujeito da pesquisa.

O genograma mostrou-se adequado para a apreensão de dados, como um instrumento de pesquisa, já que atingiu os objetivos propostos com a obtenção de resultados satisfatórios de forma prática e relativamente rápida. O processo de produção do genograma já iniciava, pouco a pouco, a história de vida dos sujeitos e, quando a "pergunta gerativa de narrativa" (Flick, 2009) era desvelada, muito já se havia dito sobre o assunto.

Nesse sentido, revelou-se, ainda, uma importante ferramenta para o pesquisador entender a história de vida contada pelos adolescentes que vivem com HIV/Aids. Além disso, por se tratarem de pessoas que viviam com uma doença de transmissão vertical, a história da transmissão e as pessoas envolvidas nesse processo eram muito abordadas durante as narrativas, o que facilitava o acompanhamento, do pesquisador, aos dados revelados pelos sujeitos.

\section{Colaboradores}

Os autores trabalharam juntos em todas as etapas de produção do manuscrito.

\section{Referências}

ALMEIDA, M.R.C.B.; LABRONICI, L.M. A trajetória silenciosa de pessoas portadoras do HIV contada pela história oral. Cienc. Saude Colet., v.12, n.1, p.263-74, 2007.

BELLATO, R.; ARAÚJO, L.F.S.; CASTRO, P. O itinerário terapêutico como uma tecnologia avaliativa da integralidade em saúde. In: PINHEIRO, R.; SILVA JUNIOR, A.G.; MATTOS, R.A. (Orgs.). Atenção básica e integralidade: contribuições para estudos de práticas avaliativas em saúde. Rio de Janeiro: Cepesc, IMS/UERJ, Abrasco, 2008. p.167-87.

BRASIL. Ministério da Saúde. Secretaria de Vigilância em Saúde. Programa Nacional de DST, Aids e Hepatites Virais. Boletim epidemiológico Aids-DST. Brasília: Ministério da Saúde, 2010.

Ministério da Saúde. Secretaria de Vigilância em Saúde. Programa Nacional de DST e Aids. Recomendações pra terapia antirretroviral em crianças e adolescentes infectados pelo HIV: manual de bolso. Brasília: Ministério da Saúde, 2009.

CARDIM, M.G. Adoecer e adolescer com HIV/Aids: experiências de trajetórias terapêuticas. 2012. Tese (Doutorado em Saúde Pública) - Instituto Fernandes Figueira, Rio de Janeiro. 2012.

CASTRO, E.K.; PICCININI, C.A. Implicações da doença orgânica crônica na infância para as relações familiares: Algumas questões teóricas. Psicol. Reflex. Crit., v.15, n.3, p.625-35, 2002.

CASTRO, L.R. Crianças e jovens na construção da cultura. Rio de Janeiro: FAPERJ, 2001. 
CHAREPE, Z.B. et al. (Re) descoberta de esperança na família da criança com doença crônica através do genograma e ecomapa. Texto Contexto Enferm., v.20, n.2, p.349-58, 2011.

COSTA, A.L.R.C. et al. O percurso na construção dos itinerários terapêuticos de famílias e redes para o cuidado. In: PINHEIRO, R.; MARTINS, P.H. (Orgs.). Avaliação em saúde na perspectiva do usuário: abordagem multicêntrica. Rio de Janeiro:

Cepesc/IMS-UERJ, 2009. p.195-202.

CRUZ, E.F. Infâncias, adolescências e Aids. Educ. Rev., v.46, n.1, p.363-84, 2007.

DELGADO, A.C.C.; MÜLLER, F. Sociologia da infância: pesquisa com crianças. Educ. Soc., v.26, n.1, p.351-60, 2005.

FLICK, U. Introdução à pesquisa qualitativa. 3.ed. Porto Alegre: Artmed, 2009.

GOFFMAN, E. Estigma: notas sobre a manipulação da identidade deteriorada. Rio de Janeiro: Guanabara, 1988.

GROPPO, L.A. Juventude: ensaios sobre sociologia e história das juventudes modernas. Rio de Janeiro: Difel, 2000.

GUARIGLIA, F.; BENTO, S.F.; HARDY, E. Adolescentes como voluntários de pesquisa e consentimento livre e esclarecido: conhecimento e opinião de pesquisadores e jovens. Cad. Saude Publica, v.22, n.1, p.53-62, 2006.

MAYALL, B. Towards a sociology of child health. Sociol. Health Illn., v.20, n.3, p.26988, 1998.

MELLO, D.B.; MOREIRA, M.C.N. A hospitalização e adoecimento pela Perspectiva de crianças e jovens portadores de fibrose cística e osteogênese imperfeita. Cienc. Saude Colet., v.15, n.2, p.247-54, 2010.

MINAYO, M.C.S. (Org.). O desafio do conhecimento: pesquisa qualitativa em saúde. 12.ed. São Paulo: Hucitec, 2010.

MOLLO-BOUVIER, S. Transformação dos modos de socialização das crianças: uma abordagem sociológica. Educ. Soc., v.26, n.1, p.351-60, 2005.

MONTANDON, C. Sociologia da infância: balanço dos trabalhos em língua inglesa. Cad. Pesqui. Fund. Carlos Chagas, v.112, n.1, p.33-60, 2001.

MOREIRA, M.C.N.; CUNHA, C.C. Repensando as práticas e dilemas no cotidiano de atenção à saúde de crianças e jovens vivendo com HIV/AIDS. Divulg. Saude Debate, v.29, n.1, p.73-92, 2003.

MOREIRA, M.C.N.; MACEDO, A.D. O protagonismo da criança no cenário hospitalar: um ensaio sobre estratégias de sociabilidade. Cienc. Saude Colet., v.14, n.2, p.645-52, 2009.

MUNIZ, J.R.; EISENSTEIN, E. Genograma: informações sobre família na (in)formação médica. Rev. Bras. Educ. Med., v.33, n.1, p.72-9, 2009.

NASCIMENTO, L.C.; ROCHA, S.M.M.; HAYES, V.E. Contribuições do genograma e do ecomapa para o estudo de famílias em enfermagem pediátrica. Texto Contexto Enferm., v.14, n.2, p.280-6, 2005.

PAIS, J.M. A construção sociológica da juventude - alguns contributos. Anal. Soc., v.25, n.1, p.139-65, 1990

PAVARINI, S.C.I. et al. Genograma: avaliando a estrutura familiar de idosos de uma unidade de saúde da família. Rev. Eletron. Enferm., v.10, n.1, p.39-50, 2008.

PEREIRA, A.P.S. et al. O genograma e o ecomapa no cuidado de enfermagem em saúde da família. Rev. Bras. Enferm., v.62, n.3, p.407-16, 2009. 
PLAISANCE, E. Para uma sociologia da pequena infância. Educ. Soc., v.25, n.86, p.221-41, 2004.

SANTA ROSA, E. Quando brincar é dizer: a experiência psicanalítica na infância. Rio de Janeiro: Relume-Dumará, 1993.

SIMMEL, G. Questões fundamentais da sociologia. Rio de Janeiro: Jorge Zahar, 2006.

SIMPIONATO, E.; CORREIA, C.C.; ROCHA, S.M.M. Histórico familiar de crianças com insuficiência Renal Crônica: coleta de dados. Rev. Bras. Enferm., v.58, n.6, p.682-6, 2005.

SIROTA, R. Emergência de uma sociologia da infância: evolução do objeto e do olhar. Cad. Pesqui. Fund. Carlos Chagas, v.112, n.1, p.112-7, 2001.

SPINDOLA, T.; SANTOS, R.S. Trabalhando com história de vida: percalços de uma pesquisa(dora)?. Rev. Esc. Enferm. USP, v.37, n.2, p.119-26, 2003.

WORLD HEALTH ORGANIZATION. UNAIDS. Aids epidemic update. Geneva, 2009.

CARDIM, M.G.; MOREIRA, M.C.N. Adolescentes como sujetos de investigación: el uso genograma como soporte para la historia de vida. Interface - Comunic., Saude, Educ., v.17, n.44, p.133-43, jan./mar. 2013.

El genograma es una descripción gráfica de la familia consanguínea de parentesco, y/o afecto, proporcionando una amplia gama de información acerca de la dinámica familiar. La propuesta de este trabajo es la reflexión sobre el marco de la creación, utilización y el análisis del proceso de utilización del genograma, como un enfoque para el desarrollo de la investigación. El diseño destaca la perspectiva de una historia temática de la vida de 14 adolescentes con la transmisión vertical de la infección por HIV. El genograma fue considerado como un recurso importante para el manejo inicial de los adolescentes, promoviendo una aproximación y una relación agradable entre el investigador y el sujeto de investigacion. El genograma se señaló también como apropriado para la recolección de datos y como una herramienta importante para \& entender la historia de vida reportada por los adolescentes.

Palabras clave: Genograma. Adolescentes. Historia de vida. 